\title{
Undifferentiated Epithelioid Sarcoma
}

National Cancer Institute

\section{Source}

National Cancer Institute. Undifferentiated Epithelioid Sarcoma. NCI Thesaurus. Code C121802.

An undifferentiated soft tissue sarcoma characterized by the presence of a malignant cellular infiltrate with epithelioid morphology. 